\title{
MOBILE SOLUTIONS IN ROAD TRANSPORT
}

\author{
Nijolè Batarliené ${ }^{1}$, Adolfas Baublys ${ }^{2}$ \\ ${ }^{1}$ Dept of Transport Management, Vilnius Gediminas Technical University, \\ Plytinès g.27,LT-10105Vilnius,Lithuania.E-mail: nijbat@ti.vtu.lt \\ ${ }^{2}$ Transport Research Institute, Vilnius Gediminas Technical University, \\ Plytinès g. 27, LT-10105 Vilnius, Lithuania.E-mail: Adolfas.Baublys@ti.vtu.lt
}

Received 16 December 2006; accepted 1 February 2007

\begin{abstract}
The article dwells on the aspects of mobile solutions of public information and transport. The work presents major decision making principles based on object positioning and a system of positioning-based GSM solutions. The newly developed remote identification systems for transport facilities and goods and passenger transport and their schematic view are presented. The main units of the remote identification system of vehicles and goods embrace: TI portal, TVIM portal, content control system (SMS, GPRS), mobile phone, the unit for stating the geographical position of vehicles and goods. Portals are designed so that the data provided by various systems of observation, such as GSM, GPS, WLAN, wireless internet, etc., can be used there. Portals (TI and TVIM) can also be used for testing, complex evaluation of monitoring functions as well as for providing the data on geographical location of objects, transmitting data to mobile telephones, etc. Purposes and functions of the portals are presented. The article describes the facility of implementing the mobile user concept, changes made in the portal pages to support the mobile users.
\end{abstract}

Keywords: transport means, goods, passenger, GSM.

\section{Introduction}

A major goal of transport policy pursued by the European Union is the creation of the unlimited unified transport market providing equal conditions for its members to compete with each other. However, the solutions made in the field of national transport are often ineffective because of the lack of information about transport mobility, logistic requirements or unforeseen changes in policy. Decision-making requires the access to the reliable information und statistical data on transport system as well as on the environment and major influencing factors.

\section{Major decision making principles based on object positioning}

When a global mobile phone system (GSM) created more than a decade ago became widely used all over the world, a basis for developing a system for positioning objects (GPS) was in place. In a variety of applications, not requiring high accuracy, object positioning may be based only on GSM technology.

A schematic view of object location based GSM decision support system is presented in Fig 1.

Mobile solutions based on object positioning are made by choosing a particular application content which is attached to a subscriber SIM. GSM connects the subscriber's cell phone to the network. A subscriber telephone is usually positioned by the global positioning or GSM positioning systems. The obtained coordinates of an object are transmitted by GSM network via the signal or GPRS channels, or through EDGE channels. The coordinates are stored in the location center and then transferred to the application database. Two portals, i.e. the public and the authority portals, are created by using the Internet [1-5]. GSM solutions based on positioning facilitate the provision of location services making them easily accessible. For designing the above services joined effort of the developers of technologies and special equipment, service providers and system developers are required.

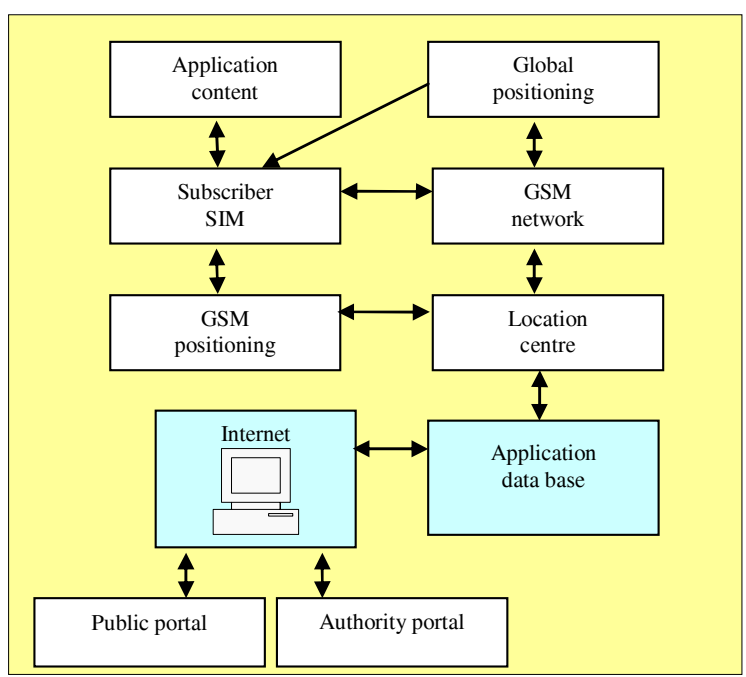

Fig 1. A system of positioning-based GSM solutions 


\section{A remote identification system for freight transport}

In solving the problems associated with vehicles and transportation of dangerous goods, one should always know an exact location of transport facility and the goods transported as well as the places of freight loading, unloading and transfer. The information on the past runs on particular routes should also be studied. This could allow us to effectively control all transport facilities as well as avoiding fire explosions of dangerous goods or other accidents. The information of any deviation from the route and other related data should be recorded.

During goods transportation a carrier (a company) should get the following data relating to:

- the location of the vehicle and whether the goods are being loaded or unloaded;

- the process of crossing the state border by the vehicle;

- the time of the vehicle's arrival at the terminal;

- $\quad$ observance of work and leisure time by the carrier;

- time of re-fuelling.

Vehicle control and freight monitoring are performed at the control room. A database (DB) is generated on the basis of the obtained information, which can be used for:

- collecting and storing the information on the route;

- coding transport facilities (e.g. loaded, not loaded);
- grouping the vehicles in order to divide the obtained information (messages);

- measuring time for determining the period of MCT activity after shutting down the engine;

- $\quad$ showing 100 previous positions of the vehicle on the map or providing textual information about it;

- providing some additional information about the state and location of the trailer;

- providing the information about the state of the refrigerator (e.g. its temperature, the temperature of recirculating air and gases).

The main units of the remote identification system of vehicles and goods embrace: TI portal, TVIM portal, content control system (SMS, GPRS), mobile phone, the unit for stating the geographical position of vehicles and goods.

A schematic view of the identification system of vehicles and goods is shown in Fig 2.

TI portal is a subsystem aimed at providing the data on vehicles. The users of the portal can obtain the required information there and use the additional portal modules and subsystems. TVIM portal (i.e. a mobile portal for common information about transport) is a subsystem performing the function of providing open information about transport for the users of the portal. Purposes and functions of the portals are presented in Table.

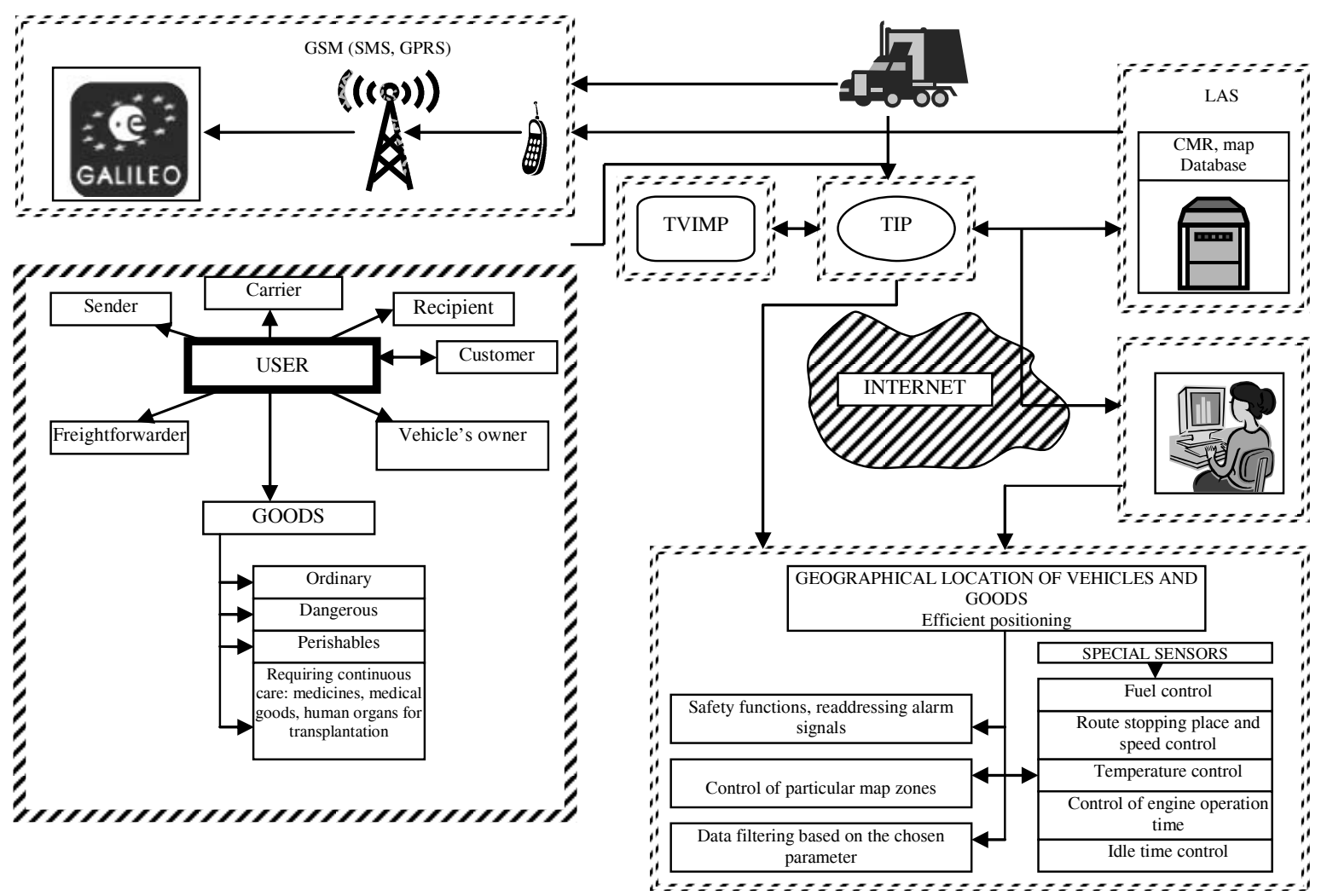

Fig 2. A system of remote identification of vehicles and goods 
Purposes and functions of the portals

\begin{tabular}{|l|}
\hline \multicolumn{1}{|c|}{ TVIM } \\
\hline Mobile component \\
\hline Static information component \\
\hline Dynamic information component \\
\hline Open statistical data component \\
\hline \multicolumn{1}{|c|}{ TI } \\
\hline Statistical component \\
\hline Visualization/location component \\
\hline User data register and its control component \\
\hline Component of communication with external systems \\
\hline LBS \\
\hline
\end{tabular}

TVIMP is designed for all users of this portal to perform the following functions:

- a mobile component allows the users to browse through a portal with a cell phone or other devices, using a WWW or WAP browser;

- $\quad$ static information component collects and automatically updates static data (e.g. documents, links, etc.);

- dynamic information component provides the dynamic information stored in the portal, i. e. news, messages/announcements from transport companies, services, etc.;

- open statistical data component provides generalized public statistical data about flows of transport, general use of roads, etc.

$\mathrm{TI}$ is designed for registered users to perform the following functions:

- $\quad$ statistical component provides statistical data on vehicle and freight traffic;

- visualization/location component deals with enquiries, providing textual and visual information from the location server (LAS) component about the location of objects;

- user data register and its control component register the portal users, allowing them to input/present the data on the monitored company's vehicles, transported goods, etc.;

- component of communication with external systems provides the interface for the portal communication with other systems;

- LBS (location-based services) implements and provides various services associated with user location.

Given such flexibility, services can be provided to a wide range of users, including large logistics companies as well as individual carriers. Both types of portals have access to highly developed mobile phone lines.

\section{A system of remote identification of passenger transport}

The developing of remote identification system for passenger transport is associated with the solution of the problem of creating a monitoring system to achieve regular bus traffic on international distant and local (urban and suburban) routes. The above system will help to control the carrier's operation on these routes, increasing traffic regularity and improving the servicing of passengers. This will also allow passengers and their relatives to get information about bus traffic, i.e. the arrival of buses on time, too early or too late. By introducing this system, a carrier (a company) will be able to get the relevant information (as an output) about the operation, i. e. the total hours worked, deviations from schedule and other violations, etc.

The main units making a remote identification system for passenger traffic are TIP, TVIMP, vehicles and passengers' unit, LAS, the Internet, GSM (SMS, GPRS), the information stored in bus station databases and the unit for stating the geographical location of passenger transport. Mobile phones are used for the identification of passengers in this system.

A schematic view of the remote identification system for passenger transport is presented in Fig 3.

The information required by a carrier (a company) on an international route includes these main items:

a) if a bus driver works according to schedule, i.e.:

- $\quad$ if he crosses the state border on time;

- $\quad$ if he arrives at bus stations on time;

- if he arrives at the destination point on time;

b) if, when arriving at the place of destination, he goes to settle some private affairs.

To get the above information a system of bus monitoring on the route should be created. To achieve this, it is necessary:

- to provide every bus with a mobile telephone number;

- $\quad$ to determine bus identificator;

- based on several control runs to make a traffic schedule on the route;

- to determine the control (check) points at:

a) the stations on the bus route;

b) at the points of state border crossing;

c) at the destination points on the route;

d) at intermediate bus stations, if there are no bus stations at each route section of 150 $200 \mathrm{~km}$;

- $\quad$ to make a schedule of monitoring bus position, i.e. determining the time when a bus should arrive at the above-mentioned control points;

- when a bus proceeds on a route, to observe and record the time of its arrival at the check points and crossing the border, as well as deviations from schedule (accurate to within few minutes). The deviations from schedule should be registered in the form of tables or graphs.

When a bus is on an international route, GSM communication should be used:

- when a bus is crossing the state border;

- when a bus arrives at bus stations on the route;

- if there are no bus stations on the route sections of $150-200 \mathrm{~km}$ it should be used when a bus passes small intermediate stations;

- when a bus arrives at the final station (its destination point); 


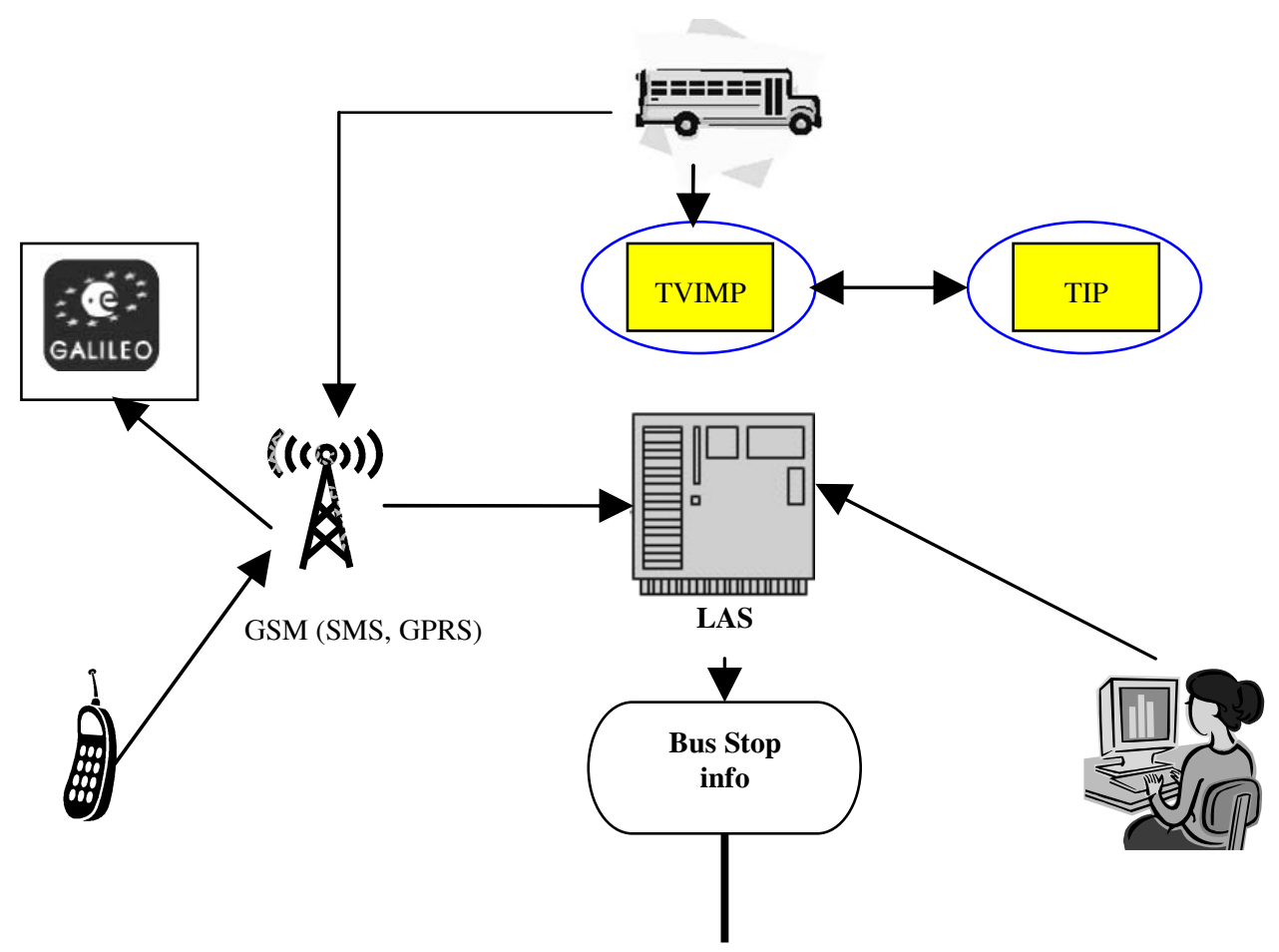

Fig 3. Remote identification system for passenger transport

- for checking 1-3 times if, on arriving at the place of destination, a bus driver uses a bus to settle his private affairs (the number of checks depends on the idle time of the bus at the final station).

The information which should be provided to a carrier (company) on a long route should be similar to this required for an international route, except for the data on the time of crossing the state border (which is not needed).

Other relevant information to be provided to passengers includes:

- the time of bus arrival at the station or small intermediate station according to schedule;

- the information about its actual arrival, when a bus is being late or ahead of schedule.

The relevant information provided to passengers' relatives should include:

- the information about bus arrival at the station or small intermediate station;

- time of actual arrival of a bus if it is being late or ahead of schedule.

The above problems should be solved both for international and long bus routes.

In solving the problems, the user himself will pay for GSM services, therefore, the frequency of their use will depend on the needs of the users or their relatives.

On local (urban or suburban) routes the most relevant information is associated with the question if a bus runs according to schedule.

To achieve regular bus traffic on local (urban or suburban) routes, GSM services should be used 3-5 times, depending on the number of check points on the route.

\section{Implementing the mobile user concept}

The mobile user concept is implemented as a part of the portal, i.e. WAP pages, stored in the server. In this way, the access to a portal via WAP browser is provided. Moreover, in realizing a mobile component, JAVA or SYMBIAN OS by user programs, the data are more easily accessed. The user program is either installed or loaded from a page. For this purpose, a special program can also be obtained from service provider.

When a user is connected to a portal, the browsersupported features are identified and a script installed in the page readdresses it to the user's page. The alternative solution is to provide the information requested by the user, sending this page to him without readdressing. In the latter case, the structure of the portal pages is not lost, however, web page scripts are not so easily read and are less comprehensible (php, jsp, aspx, or servlets).

It is more convenient to store pages with the same name nearby, extending their names according to the context, like _wap, wap2, xhtml (for example, if a menu is available, php creates an additional file - menu _wap, php, having the same links and elements as an ordinary menu).

In this design methods, a navigation scheme will remain unchanged.

In Fig 4 some changes in TVIM portal pages made to support mobile clients are shown. 


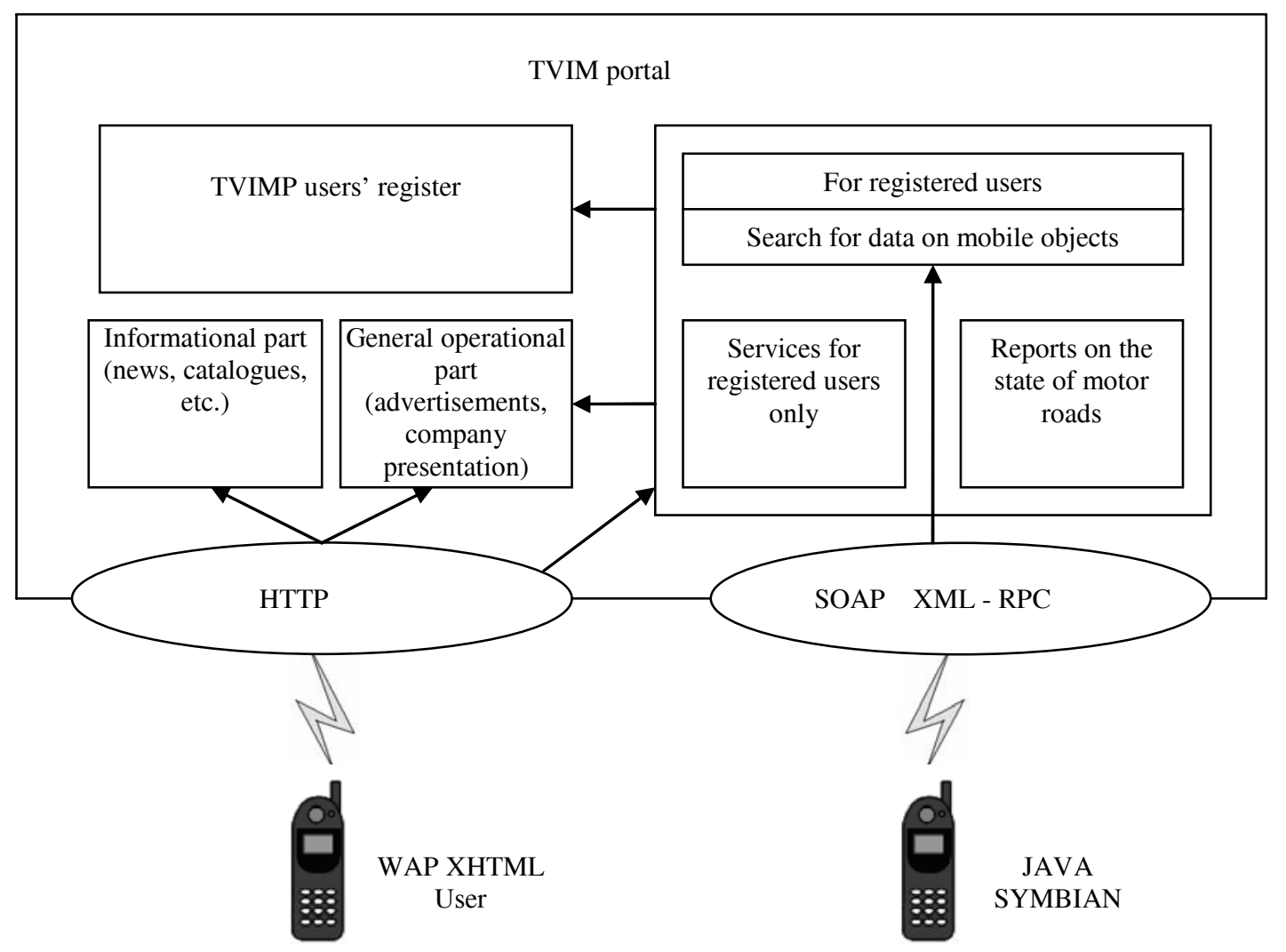

Fig 4. Changes made in the portal pages to support the mobile users

It should be noted that the portal architecture allows for adapting respective software for use in other searching systems of a similar kind, aimed at:

- continuous monitoring of dangerous cargo transportation;

- continuous monitoring of some medicines, biological substances or organs for transplantation;

- $\quad$ performing similar tasks.

These systems usually require updating of data about the mobile objects being monitored to provide the services helping to locate these objects (referred to as LBS - Location-Based Services).

The portals, dealing with the positioning of objects in GSM network, should communicate with users' mobile stations. Since the location function at the portals is performed by linking the codes of the searcher and the searched - a telephone number (IMSI), the code of every user can be used as his/her name. The telephone number of a user can also be used for his/her authorizing and for sending messages about the locating operations. A portal should also be accessed via the mobile station WAP interface. Mobile station-portal interface is required to perform one of the four functions given below:

- $\quad$ authorizing, when a WEB portal is used;

- $\quad$ using a portal WAP interface;

- controlling permission/denial via a mobile station;

- sending messages about the location to the searched.
Portals are designed so that the data provided by various systems of observation, such as GSM, GPS, WLAN, wireless internet, etc., can be used there. They can also be used for testing, complex evaluation of monitoring functions as well as for providing the data on geographical location of objects, transmitting data to mobile telephones, etc.

Any carrier using a remote identification system of vehicles and goods should:

- $\quad$ provide every vehicle driver with a mobile phone to be able to transmit information to him by sending SMS;

- appoint a person responsible for maintaining the connection with drivers or other participants in the process of transportation.

\section{Concluding remarks}

1. A system of remote identification of vehicles and goods allows the carrier to determine:

- where the vehicle is and if it is being loaded or unloaded;

- $\quad$ how the vehicle is crossing the state border;

- when the vehicle arrives at the place of destination (terminal);

- if a vehicle driver keeps to the scheduled work and leisure time;

- when the vehicle is refuelled. 
2. A system of remote identification of passenger transport allows:

a) the carrier to observe:

- if the driver keeps to schedule on the run;

- if he crosses the state border on time;

- if he arrives at the bus station (or small intermediate stations) on time;

- if a bus arrives at the final bus station on time;

- if he goes to settle his private affairs on arriving at the final bus station.

b) the passengers to know:

- when a bus should arrive at the bus station or a small intermediate station according to schedule;

- if a bus is being late or ahead of schedule. If so, to learn the actual time of bus arrival.

c) the passengers' relatives to know:

- where a bus is at the moment;

- when a bus should arrive at the bus station or a smaller intermediate station;

- $\quad$ if a bus arrives on time, and if not, to know the time of its delay or arrival ahead of schedule.

3. Mobile phones are used to identify vehicles, goods and passengers in the system of remote identification.

4. To identify goods at a distance from the containers or large packages, disposable sensors can be used. They may be made of paper and attached (glued) to packages or containers to be monitored.

5. The portals TVIM and TI are used to meet the needs of both public and private transport and all interested parties, providing the required services and performing various functions, especially those associated with vehicle monitoring. The portals can provide their users with various kinds of information, including public, legal, statistical, geographical and other types of information, as well as some confidential data based on vehicle monitoring required for the effective company performance.

6 . The works performed using the VITMOS program, as well as the experience gained, could make a basis for speeding up the integration of the transport system of Lithuania into the economic community of European and other countries

\section{References}

1. SALTENIS, S.; JENSEN, C. S. Indexing of moving objects for location-based services. In Proceedings of the 18th International Conference on Data Engineering (ICDE'02), 2002, p. 463-472.

2. SILBERSCHATZ, A.; KORTH, H. F.; SUDARSHAN, S. Database system concepts. McGraw-Hill, 4th ed., 2002.

3. LIUTKAUSKAS, V.; MATULIS, D.; PLĖ̌TTYS, R. Location-based services. Elektronika ir elektrotechnika, 2004, Nr. 3(52), p. 35-39.

4. European transport policy for 2010. White paper http://europa.eu.int/comm/energy_transport/library/lb_text e_complet_en.pdf .

5. eSafety research docs: www.cordis.lu/ist/so/esafety/publications.htm. 